\title{
The Accuracy and Correction of Fuel Consumption from Controller Area Network Broadcast
}

\section{Lijuan Wang, Jeffrey Gonder, Eric Wood, and Adam Ragatz}

National Renewable Energy Laboratory

CITATION: Wang, L., Gonder, J., Wood, E., and Ragatz, A., "The Accuracy and Correction of Fuel Consumption from Controller Area Network Broadcast," SAE Technical Paper 2017-01-7005, 2017, doi:10.4271/2017-01-7005.

Copyright $(2017$ SAE International

\begin{abstract}
Fuel consumption (FC) has always been an important factor in vehicle cost. With the advent of electronically controlled engines, the controller area network (CAN) broadcasts information about engine and vehicle performance, including fuel use. However, the accuracy of the FC estimates is uncertain. In this study, the researchers first compared CAN-broadcasted FC against physically measured fuel use for three different types of trucks, which revealed the inaccuracies of CAN-broadcast fueling estimates. To match precise gravimetric fuel-scale measurements, polynomial models were developed to correct the CAN-broadcasted FC. Lastly, the robustness testing of the correction models was performed. The training cycles in this section included a variety of drive characteristics, such as high speed, acceleration, idling, and deceleration. The mean relative differences were reduced noticeably.
\end{abstract}

\section{Introduction and Objectives}

The use of controller area network (CAN) data allows researchers quick access to important engine operating parameters. However, fuel use recorded by the CAN is derived from an algorithm with assumptions implemented in the vehicle's electronic control unit [1], and the assumptions vary among different powertrains [2]. These cause discrepancies between the estimated fuel consumption (FC) rate and the physically measured $\mathrm{FC}$ rate. The uncertainty of the estimated fuel use has been discussed previously by researchers at the National Renewable Energy Laboratory []].

To evaluate the accuracy of the estimates, CAN-broadcasted fuel rates need to be compared against fuel use from precise fuel measurements. The National Renewable Energy Laboratory's Renewable Fuels and Lubricants (ReFUEL) laboratory provided experimental data on three candidate trucks. Researchers at the ReFUEL laboratory recorded accurate FC measured from a gravimetric fuel scale and the CAN bus fuel use simultaneously.
This study had two objectives: 1) compare CAN-broadcasted FC against fuel measurements from the gravimetric fuel scale, and 2) develop models to correct the CAN FC to match the fuel-scale measurements.

\section{Test Vehicle Information}

The fuel comparison analysis included three medium/ heavy-duty trucks tested on the ReFUEL laboratory's heavy-duty chassis dynamometer, each over multiple drive cycle tests. The three trucks with unknown CAN bus algorithms were different from each other. Each of these different drive cycles comprises several repetitions of the same test. Detailed information about the trucks is presented in Table 1. Every data set contains total fuel use reported by the precise gravimetric fuel scale and by the fuel rates broadcasted from an SAE J1939 CAN.

Table 1. Details of the trucks tested

\begin{tabular}{|l|l|l|}
\hline Name & $\begin{array}{l}\text { Displacement } \\
\text { (L) }\end{array}$ & $\begin{array}{l}\text { Power } \\
\text { (hp) }\end{array}$ \\
\hline $\begin{array}{l}\text { 2011 Medium-duty diesel } \\
\text { conventional parcel } \\
\text { delivery truck }\end{array}$ & 6.7 & 200 \\
\hline $\begin{array}{l}\text { 2010 Medium-duty } \\
\text { hydraulic hybrid parcel } \\
\text { delivery truck }\end{array}$ & 6.7 & 280 \\
\hline $\begin{array}{l}\text { 2015 Day cab renewable- } \\
\text { diesel tractor }\end{array}$ & 12.9 & 455 \\
\hline
\end{tabular}

\section{Comparisons of CAN-Broadcasted and Fuel- Scale Measured FC and Fuel Economy}

Each vehicle was analyzed in separate MATLAB scripts, which adjusted for differences in fuel densities, drive cycles, and moving window size. The dynamometer and engine signals were aligned by 
performing cross-correlations [ $\underline{4}$ ] between the dynamometer vehicle speed and engine vehicle speed. Figure 1 shows the aligned fuel rates and speeds of dynamometer-measured and engine CAN-broadcasted for a randomly picked drive cycle.

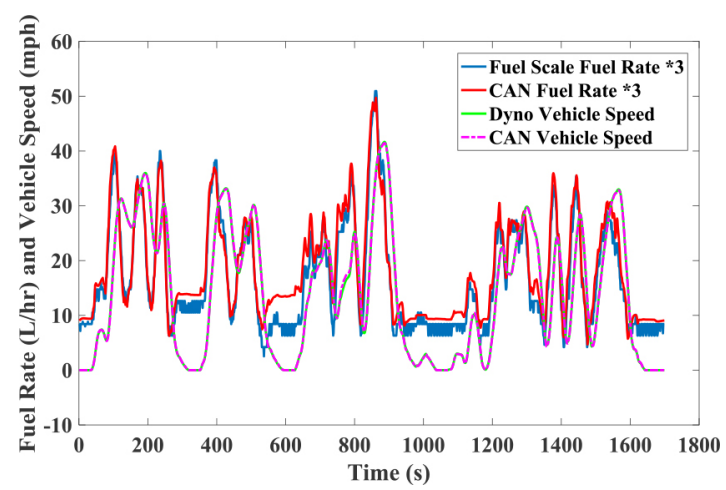

Figure 1. Aligned dynamometer measured and engine CAN broadcasted fuel rates and speeds (30-second smoothed window)

The total fuel use measured by the fuel scale was obtained by subtracting the gravimetric fuel scale's final mass from its beginning mass. Integrating CAN-broadcasted fuel rates over a certain cycle's duration gave the total CAN fuel use. The relative difference between the two sets of fuel use is defined in equation 1.

$$
\text { relativeDiff. }=\frac{\left(F C_{C A N}-F C_{\text {Scale }}\right)}{F C_{\text {Scale }}} * 100 \%
$$

Equation (1)

The mean, median, and standard deviation percent differences across all drive cycles were also calculated to reveal the general CAN fueling rate characteristics of an individual data set. Differentiating the gravimetric fuel scale's reading in time results in a real-time signal that allows this comparison to be made [3] . However, the low resolution of the ReFUEL laboratory's fuel scale resulted in a differentiated instantaneous signal that was noisy and inaccurate. Moving-average windows were applied before the comparisons. The optimal window sizes were determined empirically by observing the smoothness of the differentiated fuel-scale signal and judging whether or not it would suffice for a second-by-second comparison [3] . After smoothing the fuel rate signals, parity fuel rate plots of measurements from the fuel scale and CAN by drive cycle were generated. Figures $2, \underline{3}, \underline{4}$ show the real-time fueling scatter plot (all trucks) and percent difference bins (conventional trucks only) of example drive cycles for a medium-duty diesel conventional parcel delivery truck, a medium-duty hydraulic hybrid parcel delivery truck, and a day cab renewable-diesel tractor. The percent difference plot of the hydraulic hybrid truck is not included as the percent difference could be infinite because of the FC was zero. For the left plots with dashed green lines, the left sides represent where CAN fuel rates were over-reported compared to the fuel scale rates, while the right sides represent where CAN fuel rates were under-reported compared to the fuel scale rates.

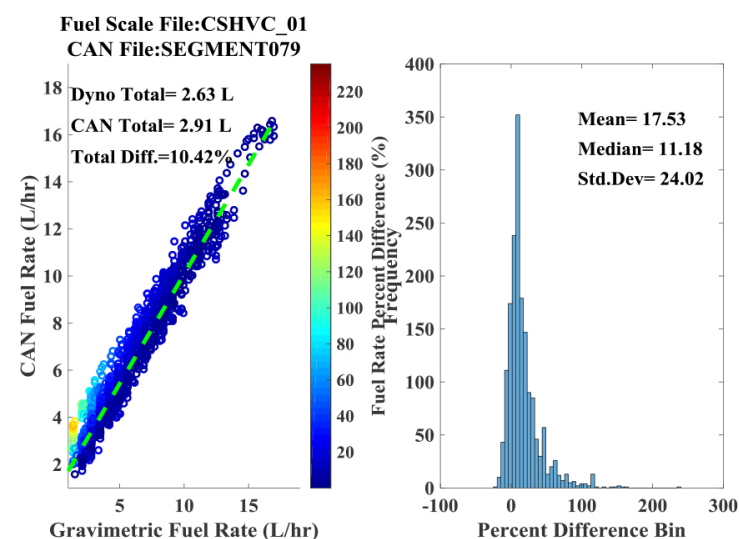

Figure 2. Real-time fuel rate parity plot between the CAN-broadcasted FC and the fuel-scale measurement and percent difference for the medium-duty diesel conventional parcel delivery truck (30-second smoothed window)

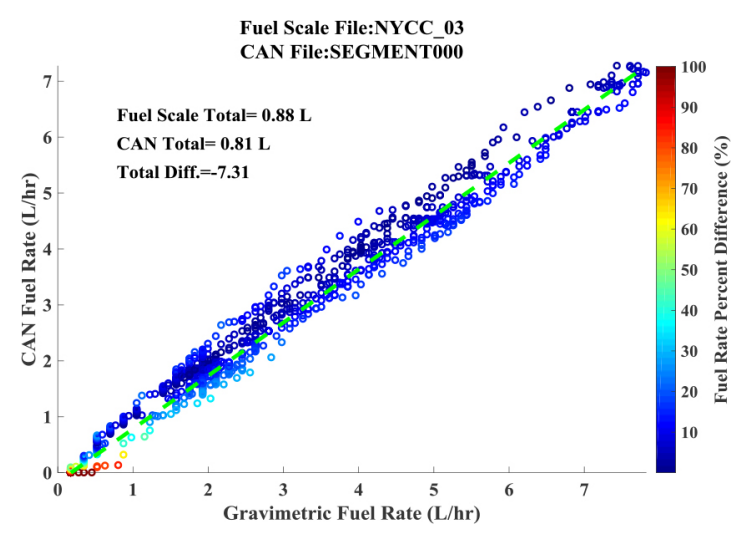

Figure 3. Real-time fuel rate parity plot between the CAN-broadcasted and fuel-scale measurement for the medium-duty hydraulic hybrid parcel delivery truck (120-second smoothed window)

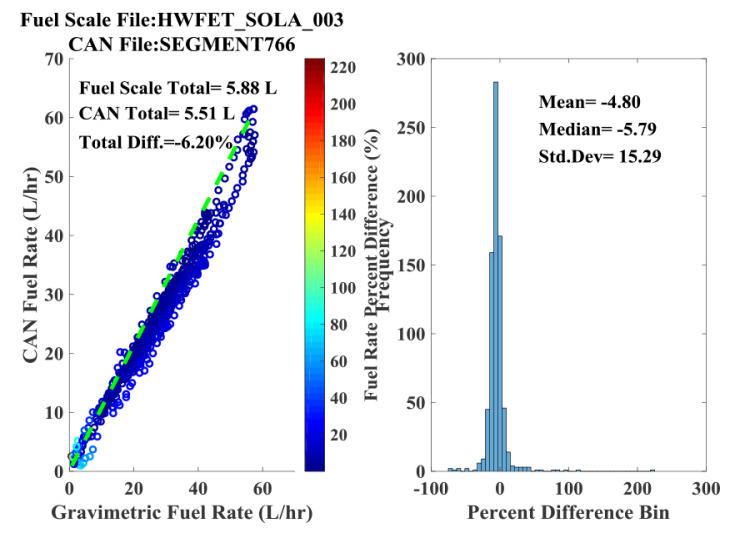

Figure 4. Real-time fuel rate parity plot between the CAN-broadcasted and fuel-scale measurement for the day cab renewable-diesel tractor (30-second smoothed window)

Tables $2, \underline{3}, \underline{4}$ show the fuel economy (FE), FC, and FC relative difference of the experimental data for the medium-duty diesel conventional parcel delivery truck, the medium-duty hydraulic hybrid parcel delivery truck, and the day cab renewable-diesel tractor. The average FC relative differences are $7.41 \%,-5.31 \%$, and $-6.51 \%$, respectively. 
Table 2. FC and FE comparison for medium-duty diesel conventional parcel delivery truck (30-second smoothed window)

\begin{tabular}{|l|l|l|l|l|l|}
\hline Drive Cycle & $\begin{array}{l}\text { CAN } \\
\text { FE } \\
\text { (mpg) }\end{array}$ & $\begin{array}{l}\text { Fuel } \\
\text { Scale } \\
\text { FE } \\
\text { (mpg) }\end{array}$ & $\begin{array}{l}\text { CAN } \\
\text { FC } \\
\text { (gal) }\end{array}$ & $\begin{array}{l}\text { Fuel } \\
\text { Scale } \\
\text { FC } \\
\text { (gal) }\end{array}$ & $\begin{array}{l}\text { FC } \\
\text { Relative } \\
\text { Diff. } \\
(\%)\end{array}$ \\
\hline CSHVC_01 & 8.67 & 9.57 & 0.77 & 0.70 & 10.42 \\
\hline CSHVC_02 & 8.74 & 9.57 & 0.76 & 0.70 & 9.10 \\
\hline CSHVC_03 & 8.77 & 9.48 & 0.76 & 0.70 & 7.92 \\
\hline CSHVC_04 & 8.70 & 9.51 & 0.76 & 0.70 & 8.91 \\
\hline CSHVC_05 & 8.78 & 9.40 & 0.76 & 0.71 & 6.69 \\
\hline HHDDT_01 & 11.06 & 12.12 & 2.34 & 2.15 & 9.15 \\
\hline HHDDT_02 & 10.69 & 11.38 & 2.42 & 2.29 & 5.97 \\
\hline HHDDT_04 & 10.67 & 11.51 & 2.43 & 2.26 & 7.75 \\
\hline HHDDT_05 & 10.72 & 11.49 & 2.42 & 2.27 & 7.00 \\
\hline HHV_01 & 7.86 & 8.25 & 2.60 & 2.48 & 5.00 \\
\hline HHV_02 & 8.17 & 8.44 & 2.49 & 2.41 & 3.24 \\
\hline HHV_03 & 8.28 & 8.56 & 2.47 & 2.38 & 3.37 \\
\hline HHV_04 & 8.27 & 8.61 & 2.47 & 2.37 & 3.95 \\
\hline NYC_01 & 6.30 & 6.80 & 0.40 & 0.37 & 7.85 \\
\hline NYC_02 & 6.48 & 7.07 & 0.39 & 0.36 & 9.04 \\
\hline NYC_03 & 6.50 & 7.17 & 0.39 & 0.35 & 10.23 \\
\hline NYC_04 & 6.60 & 7.27 & 0.38 & 0.34 & 10.33 \\
\hline & 8.54 & 9.19 & 1.47 & 1.38 & 7.41 \\
\hline & & & & & \\
\hline Mean & & & & & \\
\hline
\end{tabular}

Table 3. FE and FC comparison for medium-duty hydraulic hybrid parcel delivery truck (120-second smoothed window)

\begin{tabular}{|l|l|l|l|l|l|}
\hline Drive Cycle & $\begin{array}{l}\text { CAN } \\
\text { FE } \\
\text { (mpg) }\end{array}$ & $\begin{array}{l}\text { Fuel } \\
\text { Scale FE } \\
\text { (mpg) }\end{array}$ & $\begin{array}{l}\text { CAN } \\
\text { FC } \\
\text { (gal) }\end{array}$ & $\begin{array}{l}\text { Fuel } \\
\text { Scale } \\
\text { FC } \\
\text { (gal) }\end{array}$ & $\begin{array}{l}\text { FC } \\
\text { Relative } \\
\text { Diff. } \\
(\%)\end{array}$ \\
\hline NYCC_02 & 11.44 & 10.67 & 0.22 & 0.23 & -8.07 \\
\hline NYCC_03 & 11.45 & 10.76 & 0.21 & 0.23 & -7.31 \\
\hline NYCC_04 & 11.62 & 11.11 & 0.21 & 0.23 & -5.87 \\
\hline NYCC_05 & 11.58 & 10.84 & 0.21 & 0.23 & -7.74 \\
\hline CSHVC_01 & 13.42 & 13.40 & 0.49 & 0.50 & -1.31 \\
\hline CSHVC_02 & 13.50 & 12.95 & 0.49 & 0.51 & -5.28 \\
\hline CSHVC_03 & 13.24 & 12.79 & 0.50 & 0.52 & -4.59 \\
\hline CSHVC_04 & 13.37 & 12.84 & 0.49 & 0.52 & -5.16 \\
\hline CSHVC_05 & 13.36 & 12.76 & 0.49 & 0.52 & -5.64 \\
\hline HHDDT_01 & 12.66 & 12.20 & 2.04 & 2.13 & -4.51 \\
\hline HHDDT_02 & 11.60 & 10.96 & 2.22 & 2.38 & -6.48 \\
\hline HHDDT_03 & 11.87 & 11.31 & 2.17 & 2.30 & -5.56 \\
\hline HHDDT_04 & 11.89 & 11.30 & 2.17 & 2.30 & -5.84 \\
\hline HHDDT_05 & 12.16 & 11.63 & 2.12 & 2.24 & -5.21 \\
\hline HHDDT_06 & 11.80 & 11.27 & 2.19 & 2.31 & -5.31 \\
\hline HHV_01 & 10.95 & 10.65 & 1.77 & 1.84 & -3.95 \\
\hline HHV_02 & 10.48 & 10.14 & 1.89 & 1.98 & -4.53 \\
\hline HHV_03 & 10.56 & 10.24 & 1.87 & 1.96 & -4.23 \\
\hline HHV_04 & 10.52 & 10.21 & 1.88 & 1.97 & -4.24 \\
\hline Mean & 11.97 & 11.47 & 1.24 & 1.31 & -5.31 \\
\hline & & & & & \\
\hline
\end{tabular}

Table 4. FE and FC comparison for day cab renewable-diesel tractor (30-second smoothed window)

\begin{tabular}{|c|c|c|c|c|c|}
\hline Drive Cycle & $\begin{array}{l}\text { CAN } \\
\text { FE } \\
(\mathrm{mpg})\end{array}$ & $\begin{array}{l}\text { Fuel } \\
\text { Scale } \\
\text { FE } \\
\text { (mpg) }\end{array}$ & $\begin{array}{l}\text { CAN } \\
\text { FC } \\
\text { (gal) }\end{array}$ & $\begin{array}{l}\text { Fuel } \\
\text { Scale } \\
\text { FC } \\
\text { (gal) }\end{array}$ & $\begin{array}{l}\text { FC } \\
\text { Relative } \\
\text { Diff. (\%) }\end{array}$ \\
\hline HHDDT_02 & 7.02 & 6.53 & 3.70 & 3.96 & -6.38 \\
\hline HHDDT_03 & 7.04 & 6.55 & 3.70 & 3.95 & -6.37 \\
\hline HHDDT_04 & 7.10 & 6.64 & 3.66 & 3.89 & -5.94 \\
\hline HHDDT_05 & 7.10 & 6.60 & 3.67 & 3.93 & -6.51 \\
\hline COMMUT_05 & 6.37 & 5.87 & 0.62 & 0.67 & -7.27 \\
\hline COMMUT_07 & 6.37 & 5.88 & 0.62 & 0.67 & -7.01 \\
\hline COMMUT_08 & 6.41 & 5.90 & 0.62 & 0.67 & -7.37 \\
\hline COMMUT_09 & 6.39 & 5.92 & 0.62 & 0.66 & -6.71 \\
\hline COMMUT_10 & 6.41 & 5.92 & 0.62 & 0.67 & -7.00 \\
\hline COMMUT_11 & 6.91 & 6.52 & 1.48 & 1.55 & -4.81 \\
\hline HWFET_03 & 7.01 & 6.51 & 1.46 & 1.55 & -6.20 \\
\hline HWFET_04 & 7.00 & 6.47 & 1.45 & 1.57 & -7.19 \\
\hline HWFET_05 & 6.98 & 6.44 & 1.46 & 1.57 & -7.17 \\
\hline HWFET_06 & 6.92 & 6.53 & 1.47 & 1.55 & -5.25 \\
\hline Mean & 6.79 & 6.30 & 1.80 & 1.92 & -6.51 \\
\hline
\end{tabular}

$\underline{\text { Figures } 5}, \underline{6}, \underline{7}$ demonstrate the parity plots of average $\mathrm{FE}$ and FC and relative difference for the medium-duty diesel conventional parcel delivery truck, the medium-duty hydraulic hybrid parcel delivery truck, and the day cab renewable-diesel tractor, together with coefficients of determination $\left(\mathrm{R}^{2}\right)$ between the CAN broadcasted and fuel-scale measurements. The average FE and FC and relative differences showed on the plots are in agreement with the values in the above tables.
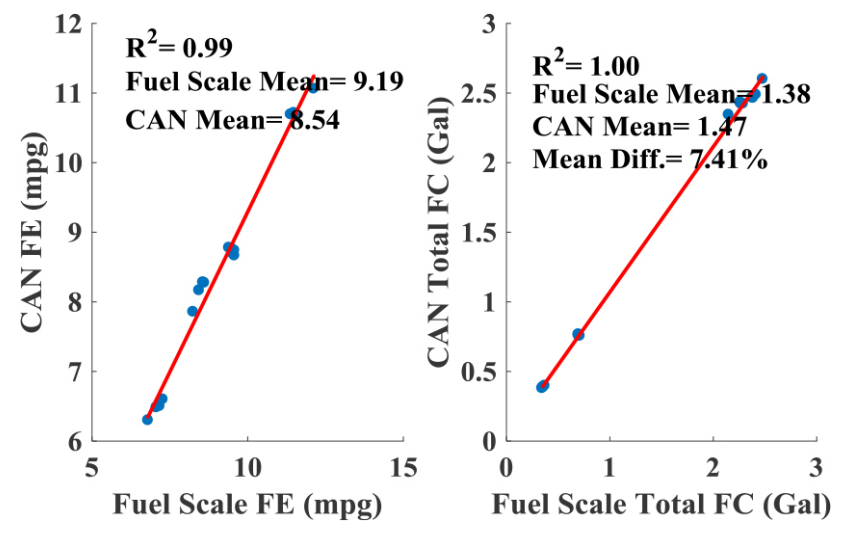

Figure 5. FE and FC parity plots between CAN-broadcasted and fuel-scale measurement for the medium-duty diesel conventional parcel delivery truck (30-second smoothed window) 

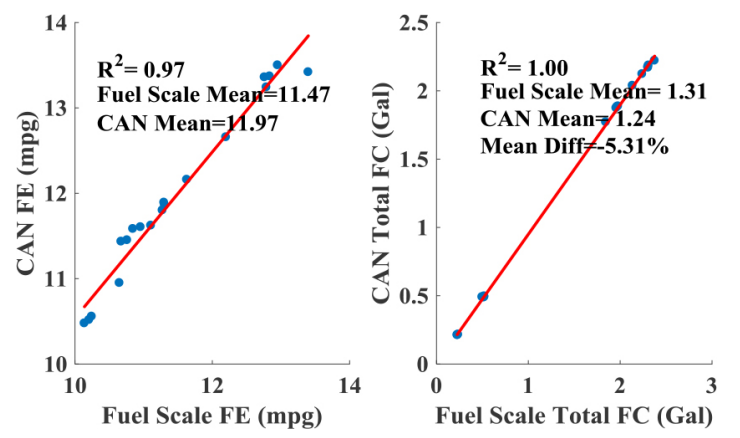

Figure 6. FE and FC parity plot between CAN-broadcasted and fuel-scale measurements for the medium-duty hydraulic hybrid parcel delivery truck (120-second smooth window)
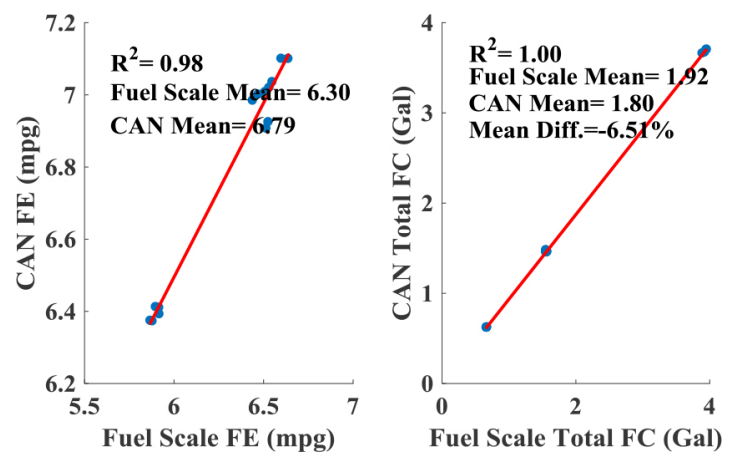

Figure 7. FE and FC parity plot between CAN-broadcasted and fuel-scale measurement for the day cab renewable-diesel tractor (30-second smoothed window)

\section{Development of Model to Correct CAN- Broadcasted Fuel Rates}

Original equipment manufacturers provide data via the CAN using comprehensive algorithms, which take into consideration parameters such as vehicle speed, engine speed, distance, fuel volume used, and other factors [2]. Since the CAN measures FC via algorithms and not from actual fuel flow, there is inherent error in those calculations, as discussed previously. Models were developed to adjust the CAN fuel use to match the more accurate fuel use from gravimetric fuel scales.

The goal of the CAN fuel use correction method is to find a relatively simple and effective model. It follows that a correction model would include a combination of the original CAN-measured fuel rate, vehicle speed, vehicle acceleration, engine speed, engine oil temperature, and ambient temperature.

The calibration of the developed model included selecting the most effective input parameters. The top three best models were obtained when the correction models were expressed as the adjusted CAN FC rates as functions of the original CAN FC only; original CAN and vehicle speed; and original CAN, vehicle speed, and vehicle acceleration (equations $2, \underline{3}, \underline{4}$ ).

$$
\begin{gathered}
C A N_{a d j}=a * C A N_{o r i g}+b \\
C A N_{a d j}=a * C A N_{o r i g}+b * V e h S p d+c \\
C A N_{a d j}=a * C A N_{o r i g}+b * V e h S p d+c * V e h A c c+d
\end{gathered}
$$

where $C A N_{a d j}$ is the adjusted CAN FC, $C A N_{\text {orig }}$ is the original CAN FC, VehSpd is the vehicle speed, and VehAcc is the vehicle acceleration. The parameters $a, b, c$, and $d$ are constant coefficients which are estimated by performing the least square method [ $\underline{5}]$. The coefficients for each vehicle are a unique set of number values.

To develop the CAN FC correction model, each of the test cycles was taken as a training cycle, and rest of them were used as testing cycles. The performance results of the correction models for the mediumduty diesel conventional parcel delivery truck are summarized in Table 5. As observed from the mean FC relative differences, the model, including the original CAN, vehicle speed, and acceleration (equation 4) using CSHVC_03 as the training cycle, gave the best performance result with a mean $\mathrm{FC}$ relative difference of $-0.06 \%$. Overall, when applying different models and training drive cycles, the adjusted CAN FCs have noticeably lower relative differences (-3.55\% to $2.63 \%)$ than those of the original CAN FCs $(3.24 \%$ to $10.42 \%)$.

Table 5. Performance results of applying different correction models for mediumduty diesel conventional parcel delivery truck (30-second smoothed window)

\begin{tabular}{|l|l|l|l|}
\hline \multirow{2}{*}{ Training Cycle } & \multicolumn{2}{l|}{ FC Relative Diff. (\%) } \\
\cline { 2 - 4 } & Model & \multicolumn{2}{l|}{} \\
\cline { 2 - 4 } & a*CAN+b & $\begin{array}{l}\text { a*VehSpd+ } \\
\text { b*CAN+c }\end{array}$ & $\begin{array}{l}\text { a*VehSpd+ } \\
\text { b*VehAcc+ } \\
\text { c*CAN+d }\end{array}$ \\
\hline CSHVC_01 & -1.46 & -1.59 & -2.03 \\
\hline CSHVC_02 & -0.81 & -0.90 & -1.02 \\
\hline CSHVC_03 & 0.33 & 0.21 & -0.06 \\
\hline CSHVC_04 & -0.59 & -0.69 & -0.87 \\
\hline CSHVC_05 & 1.48 & 1.29 & 1.70 \\
\hline HHDDT_01 & -3.55 & -3.27 & -3.10 \\
\hline HHDDT_02 & -0.12 & -0.25 & -0.13 \\
\hline HHDDT_04 & -2.00 & -1.82 & -1.71 \\
\hline HHDDT_05 & -1.04 & -0.97 & -0.92 \\
\hline HHV_01 & -0.48 & -0.44 & -1.46 \\
\hline HHV_02 & 2.34 & 2.39 & 1.56 \\
\hline HHV_03 & 2.02 & 2.02 & 0.75 \\
\hline HHV_04 & 1.53 & 1.53 & 2.63 \\
\hline NYC_01 & 2.33 & 2.61 & 0.64 \\
\hline NYC_02 & 1.66 & 1.85 & \\
\hline NYC_03 & 0.18 & 0.59 & 0.60 \\
\hline NYC_04 & 0.38 & & \\
\hline
\end{tabular}

Figure 8 illustrates the comparison of the adjusted CAN FC against the original CAN FC and fuel-scale measurement for the mediumduty diesel conventional parcel delivery truck when applying the optimal model (equation 4, using CSHVC_03 as the training cycle). The adjusted CAN FC line matches more closely to the fuel scale line. The breakdown of the FC relative differences of each drive cycle 
is shown in Table 6 . By comparing Table 2 and Table 6 , we can see that the $\mathrm{FC}$ relative differences are reduced dramatically when applying the optimal model ( $7.41 \%$ versus $-0.06 \%$ mean difference).
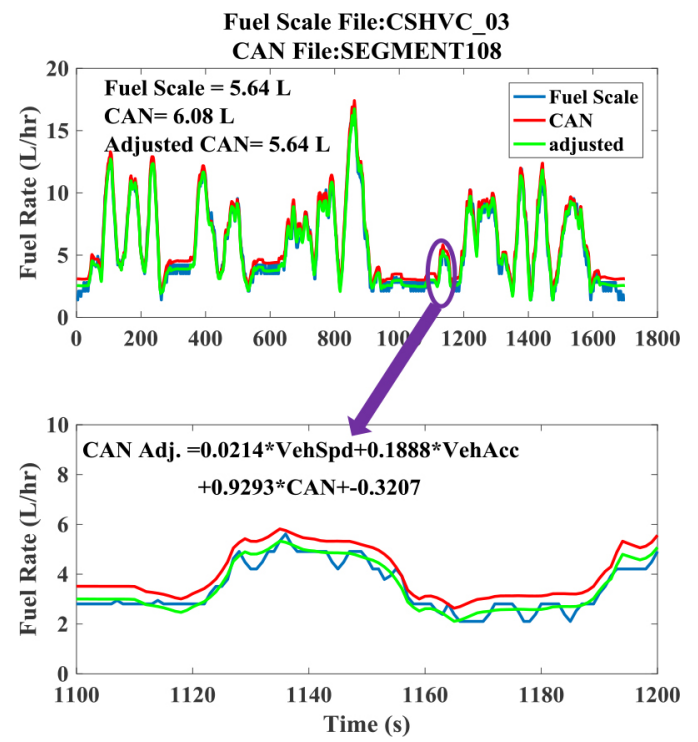

Figure 8. Comparison of adjusted CAN fuel rates against original CAN fuel rates and fuel-scale measurement for the medium-duty diesel conventional parcel delivery truck (30-second smoothed window).

Table 6. Comparison of adjusted CAN FC against fuel-scale measurement for medium-duty diesel conventional parcel delivery truck when applying optimal model (30-second smoothed window)

\begin{tabular}{|l|l|l|l|l|l|}
\hline Drive Cycle & $\begin{array}{l}\text { Adjusted } \\
\text { CAN FE } \\
\text { (mpg) }\end{array}$ & $\begin{array}{l}\text { Fuel } \\
\text { Scale } \\
\text { FE } \\
\text { (mpg) }\end{array}$ & $\begin{array}{l}\text { Adjusted } \\
\text { CAN FC } \\
\text { (gal) }\end{array}$ & $\begin{array}{l}\text { Fuel } \\
\text { Scale } \\
\text { FC } \\
\text { (gal) }\end{array}$ & $\begin{array}{l}\text { FC } \\
\text { Relative } \\
\text { Diff. } \\
(\%)\end{array}$ \\
\hline CSHVC_01 & 9.36 & 9.57 & 0.71 & 0.70 & 2.27 \\
\hline CSHVC_02 & 9.44 & 9.57 & 0.70 & 0.70 & 1.05 \\
\hline CSHVC_03 & 9.46 & 9.48 & 0.70 & 0.70 & -0.03 \\
\hline CSHVC_04 & 9.40 & 9.51 & 0.71 & 0.70 & 0.85 \\
\hline CSHVC_05 & 9.48 & 9.40 & 0.70 & 0.71 & -1.20 \\
\hline HHDDT_01 & 11.58 & 12.12 & 2.24 & 2.15 & 4.31 \\
\hline HHDDT_02 & 11.20 & 11.38 & 2.31 & 2.29 & 1.18 \\
\hline HHDDT_04 & 11.18 & 11.51 & 2.32 & 2.26 & 2.87 \\
\hline HHDDT_05 & 11.22 & 11.49 & 2.31 & 2.27 & 2.16 \\
\hline HHV_01 & 8.37 & 8.25 & 2.44 & 2.48 & -1.44 \\
\hline HHV_02 & 8.70 & 8.44 & 2.34 & 2.41 & -3.06 \\
\hline HHV_03 & 8.82 & 8.56 & 2.32 & 2.38 & -2.90 \\
\hline HHV_04 & 8.81 & 8.61 & 2.32 & 2.37 & -2.35 \\
\hline NYC_01 & 6.96 & 6.80 & 0.36 & 0.37 & -2.43 \\
\hline NYC_02 & 7.18 & 7.07 & 0.35 & 0.36 & -1.52 \\
\hline NYC_03 & 7.20 & 7.17 & 0.35 & 0.35 & -0.40 \\
\hline NYC_04 & 7.31 & 7.27 & 0.34 & 0.34 & -0.35 \\
\hline Mean & 9.16 & 9.19 & 1.38 & 1.38 & -0.06 \\
\hline
\end{tabular}

$\underline{\text { Figure } 9}$ shows the real-time fueling scatter plot of the adjusted CAN $\mathrm{FC}$ and fuel-scale measured use and the percent difference bins of example drive cycles. Figure 10 demonstrates the parity plots for the medium-duty diesel conventional parcel delivery truck. By comparing $\underline{\text { Table } 2}$ with Table 6 and Figure 5 with Figure 10, we can see that the accuracy of the adjusted CAN FC was noticeably improved.

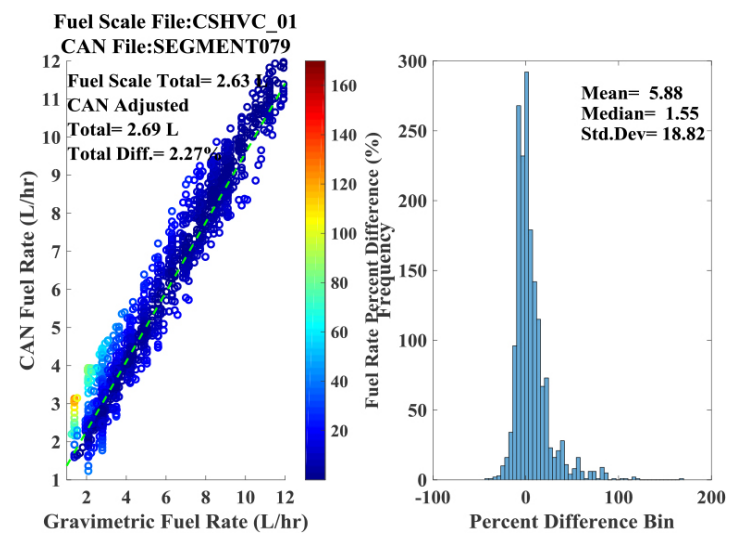

Figure 9. Real-time fuel rate parity plot between adjusted CAN FC and fuel-scale measurements and percent difference for the medium-duty diesel conventional parcel delivery truck (30-second smoothed window)

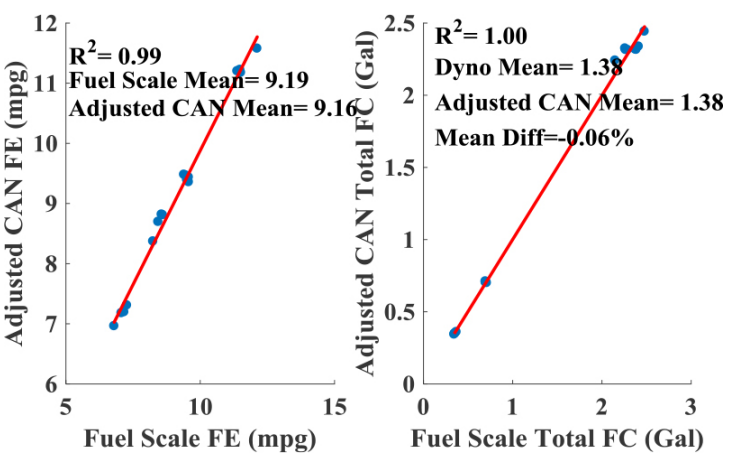

Figure 10. FE and FC parity plot between adjusted CAN FC and fuel-scale measurement for the medium-duty diesel conventional parcel delivery truck (30-second smoothed window)

In a similar way, Table 7 shows the performance results of the correction models for the medium-duty hydraulic hybrid parcel delivery truck. Including the original CAN fuel rate and vehicle speed (equation 3) and using HHV_04 as a training cycle, the model gave the best performance with a mean FC relative difference of $0.03 \%$. Overall, when applying different models and training drive cycles, the adjusted CAN FCs have noticeably lower relative differences $(-2.22 \%$ to $2.79 \%$ ) than the original CAN FCs $(1.31 \%$ to $8.07 \%)$.

Figure 11 exemplifies the comparison of the adjusted CAN fuel rates against the original CAN fuel rates and fuel-scale measurement for the medium-duty hydraulic hybrid parcel delivery truck when applying the optimal model (equation 3 using HHV_04 as the training cycle). The adjusted CAN FC line matches the fuel-scale line more closely. The breakdown of the FC relative differences of each drive cycle is shown in Table 8. By comparing Table 3 with $\underline{\text { Table } 8}$ and Figure 6 with Figure 13, we can see that the FC relative difference was reduced noticeably when applying the optimal model ( $-5.31 \%$ versus $0.03 \%$ mean difference). 
Table 7. Performance results of applying different correction models for mediumduty hydraulic hybrid parcel delivery truck (120-second smoothed window).

\begin{tabular}{|c|c|c|c|}
\hline \multirow{3}{*}{ Training Cycle } & \multicolumn{3}{|c|}{ FC Relative Diff. (\%) } \\
\hline & \multicolumn{3}{|l|}{ Model } \\
\hline & $a * C A N+b$ & $\begin{array}{l}a^{*} \text { VehSpd+ } \\
b^{*} \text { CAN }+c\end{array}$ & $\begin{array}{l}a * \text { VehSpd+ } \\
\text { b*VehAcc }+ \\
c * \text { CAN+d }\end{array}$ \\
\hline NYCC 02 & 3.39 & 2.79 & 5.20 \\
\hline NYCC 03 & 1.34 & 1.20 & 1.96 \\
\hline NYCC_04 & 1.79 & 1.46 & 2.69 \\
\hline NYCC_05 & 2.29 & 2.00 & 3.04 \\
\hline CSHVC 01 & -3.81 & -5.4 & -3.37 \\
\hline CSHVC 02 & -0.07 & -2.06 & -0.25 \\
\hline CSHVC_03 & -0.65 & -2.07 & -0.63 \\
\hline CSHVC_04 & -0.25 & -2.22 & 0.30 \\
\hline CSHVC_05 & 0.29 & -1.76 & 0.32 \\
\hline HHDDT_01 & -0.12 & -1.41 & -1.37 \\
\hline HHDDT_02 & 2.11 & 2.25 & 1.96 \\
\hline HHDDT_03 & 0.68 & 0.89 & 0.32 \\
\hline HHDDT_04 & 1.48 & 1.59 & 1.22 \\
\hline HHDDT_05 & 0.89 & 0.34 & 0.35 \\
\hline HHDDT_06 & 0.80 & 1.17 & 0.75 \\
\hline HHV_01 & -1.23 & -0.24 & -1.60 \\
\hline HHV_02 & -0.44 & 0.75 & -1.27 \\
\hline HHV_03 & -0.49 & 0.91 & -0.64 \\
\hline HHV_04 & -0.77 & 0.03 & -2.04 \\
\hline
\end{tabular}

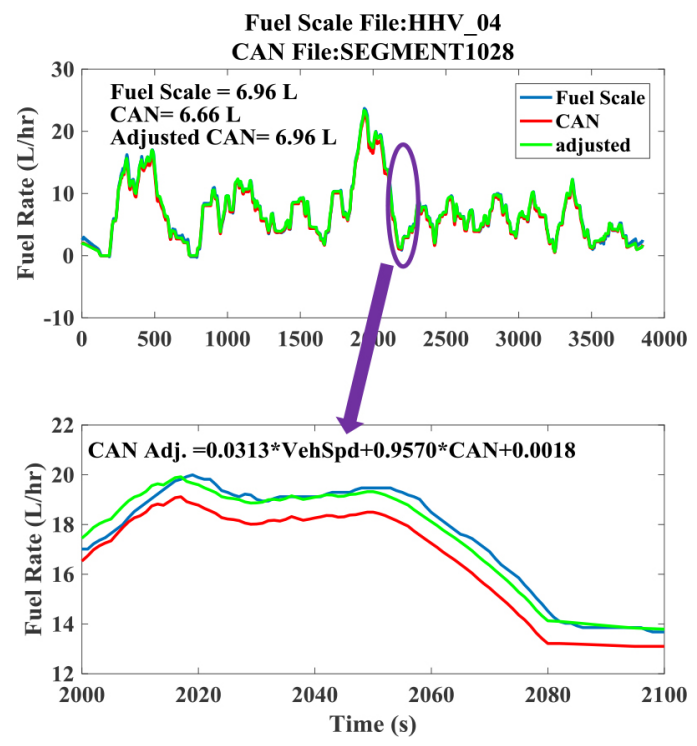

Figure 11. Comparison of adjusted CAN fuel rates against original CAN fuel rates and fuel scale measurement for the medium-duty diesel conventional parcel delivery truck (120-second smoothed window).
Table 8. Comparison of adjusted CAN FC against fuel scale measurement for medium-duty hydraulic hybrid parcel delivery truck when applying optimal model (120-second smoothed window)

\begin{tabular}{|c|c|c|c|c|c|}
\hline Drive Cycle & $\begin{array}{l}\text { CAN } \\
\text { FE } \\
(\mathrm{mpg})\end{array}$ & $\begin{array}{l}\text { Fuel } \\
\text { Scale FE } \\
\text { (mpg) }\end{array}$ & $\begin{array}{l}\text { CAN } \\
\text { FC } \\
\text { (gal) }\end{array}$ & $\begin{array}{l}\text { Fuel } \\
\text { Scale } \\
\text { FC } \\
(\text { gal) }\end{array}$ & $\begin{array}{l}\text { FC } \\
\text { Relativ } \\
\text { e Diff. } \\
(\%)\end{array}$ \\
\hline NYCC_02 & 10.87 & 10.67 & 0.23 & 0.23 & -3.27 \\
\hline NYCC_03 & 10.88 & 10.76 & 0.23 & 0.23 & -2.46 \\
\hline NYCC_04 & 11.03 & 11.11 & 0.22 & 0.23 & -0.82 \\
\hline NYCC_05 & 11.00 & 10.84 & 0.22 & 0.23 & -2.82 \\
\hline CSHVC_01 & 12.56 & 13.40 & 0.52 & 0.50 & 5.43 \\
\hline CSHVC_02 & 12.63 & 12.95 & 0.52 & 0.51 & 1.25 \\
\hline CSHVC_03 & 12.41 & 12.79 & 0.53 & 0.52 & 1.79 \\
\hline CSHVC 04 & 12.52 & 12.84 & 0.53 & 0.52 & 1.28 \\
\hline CSHVC_05 & 12.51 & 12.76 & 0.53 & 0.52 & 0.76 \\
\hline HHDDT_01 & 11.92 & 12.20 & 2.16 & 2.13 & 1.40 \\
\hline HHDDT_02 & 11.02 & 10.96 & 2.34 & 2.38 & -1.51 \\
\hline HHDDT_03 & 11.24 & 11.31 & 2.30 & 2.30 & -0.34 \\
\hline HHDDT_04 & 11.27 & 11.30 & 2.29 & 2.30 & -0.61 \\
\hline HHDDT_05 & 11.50 & 11.63 & 2.25 & 2.24 & 0.26 \\
\hline HHDDT_06 & 11.19 & 11.27 & 2.31 & 2.31 & -0.12 \\
\hline HHV_01 & 10.45 & 10.65 & 1.86 & 1.84 & 0.63 \\
\hline HHV_02 & 10.04 & 10.14 & 1.97 & 1.98 & -0.34 \\
\hline HHV_03 & 10.11 & 10.24 & 1.96 & 1.96 & 0.04 \\
\hline HHV_04 & 10.07 & 10.21 & 1.97 & 1.97 & -0.01 \\
\hline Mean & 11.33 & 11.47 & 1.31 & 1.31 & 0.03 \\
\hline
\end{tabular}

Figure 12 shows the real-time fueling scatter plot of the adjusted CAN FC and fuel-scale use and the percent difference bins of the example drive cycles. Figure 13 demonstrates the parity plots for the medium-duty hydraulic hybrid parcel delivery truck. By comparing $\underline{\text { Table } 4}$ with Table 9 and Figure 6 with Figure 13 , we can see that the accuracy of the adjusted CAN FC was noticeably improved.

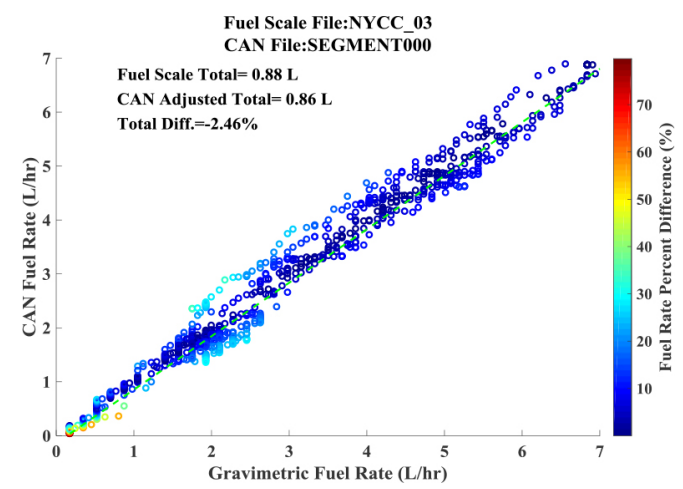

Figure 12. Real-time fuel rate parity plot between adjusted CAN FC and fuel-scale measurement and percent difference for the medium-duty hydraulic hybrid parcel delivery truck (120-second smoothed window) 

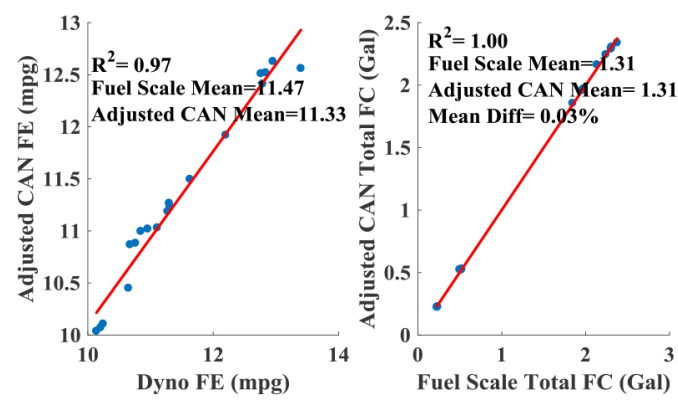

Figure 13. FE and FC parity plot between adjusted CAN FC and fuel scale measurement for the medium-duty hydraulic hybrid parcel delivery truck (120-second smoothed window)

Likewise, Table 9 presents the performance results of the correction models for the day cab renewable-diesel tractor. The simplest model (equation 2) using HHV_04 as the training cycle gave the best performance with a mean FC relative difference of $0.06 \%$. Overall, the adjusted CAN FCs when applying different models and training drive cycles have noticeably lower relative differences $(-1.77 \%$ to $1.08 \%)$ than the original CAN FCs (-4.81\% to $-7.37 \%)$.

Table 9. Performance results of applying different correction models for day cab renewable-diesel tractor (30-second smoothed window).

\begin{tabular}{|c|c|c|c|}
\hline \multirow{3}{*}{ Training Cycle } & \multicolumn{3}{|c|}{ FC Relative Diff. (\%) } \\
\hline & \multicolumn{3}{|l|}{ Model } \\
\hline & $a * C A N+b$ & $\begin{array}{l}\text { a*VehSpd }+ \\
b^{*} \text { CAN }+c\end{array}$ & $\begin{array}{l}a^{*} \text { VehSpd }+ \\
b^{*} \text { VehAcc }+ \\
c^{*} \text { CAN }+d\end{array}$ \\
\hline HHDDT_02 & -0.38 & -0.37 & -0.27 \\
\hline HHDDT_03 & -0.28 & -0.27 & -0.22 \\
\hline HHDDT_04 & -0.77 & -0.77 & -0.46 \\
\hline HHDDT_05 & -0.27 & -0.27 & 0.06 \\
\hline COMMUT_05 & 0.42 & 0.20 & -0.27 \\
\hline COMMUT_07 & 0.30 & 0.18 & 0.21 \\
\hline COMMUT_08 & 0.83 & 0.74 & 0.58 \\
\hline COMMUT_09 & 0.06 & -0.20 & -0.08 \\
\hline COMMUT_10 & 0.49 & 0.27 & 0.22 \\
\hline COMMUT_11 & -1.77 & -1.32 & -0.83 \\
\hline HWFET_03 & -0.15 & -1.37 & -1.37 \\
\hline HWFET_04 & 1.08 & 2.93 & 3.12 \\
\hline HWFET_05 & 0.90 & 0.81 & 0.81 \\
\hline HWFET_06 & -1.24 & 0.14 & 0.24 \\
\hline
\end{tabular}

Figure 14 shows the comparison of the adjusted CAN fuel rates against the original CAN fuel rates and fuel-scale measurements for the day cab renewable-diesel tractor when applying the optimal model (equation 2 using COMMUT_09 as the training cycle). The adjusted CAN FC matches the fuel-scale measurement better. The breakdown of the FC relative differences of each drive cycle is shown in Table 10. By comparing Table 4 and Table 10, we can see that the FC relative difference was reduced noticeably when applying the optimal model (-6.51\% versus $0.06 \%$ mean difference).
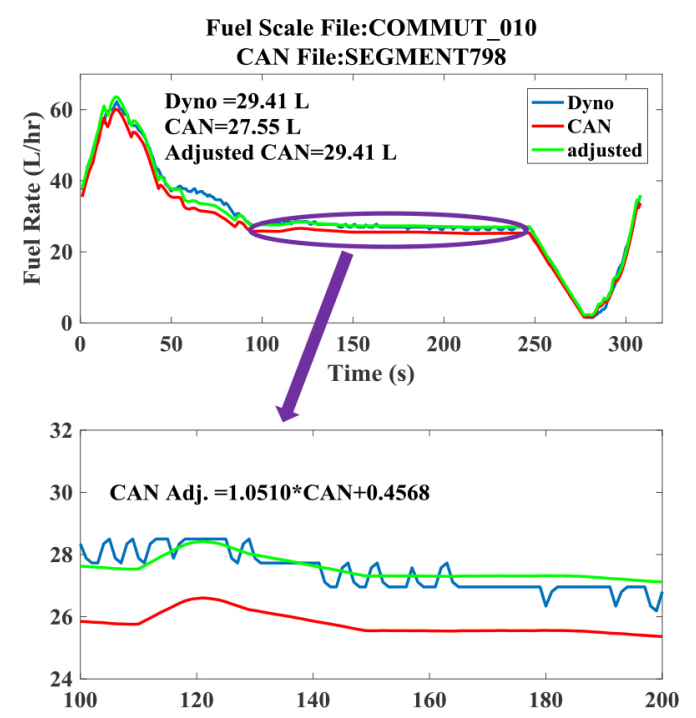

Figure 14. Comparison of adjusted CAN fuel rates against original CAN fuel rates and fuel scale measurement for day cab renewable-diesel tractor (30-second smoothed window).

Table 10. Comparison of adjusted CAN FC against fuel-scale measurement for the day cab renewable-diesel tractor when applying the optimal model (30-second smoothed window)

\begin{tabular}{|l|l|l|l|l|l|}
\hline Drive Cycle & $\begin{array}{l}\text { CAN } \\
\text { FE } \\
(\mathrm{mpg})\end{array}$ & $\begin{array}{l}\text { Fuel } \\
\text { Scale } \\
\text { FE } \\
(\mathrm{mpg})\end{array}$ & $\begin{array}{l}\text { CAN } \\
\text { FC } \\
\text { (gal) }\end{array}$ & $\begin{array}{l}\text { Fuel } \\
\text { Scale } \\
\text { FC } \\
\text { (gal) }\end{array}$ & $\begin{array}{l}\text { FC } \\
\text { Relativ } \\
\text { e Diff. } \\
(\%)\end{array}$ \\
\hline HHDDT_02 & 6.52 & 6.53 & 3.98 & 3.96 & 0.72 \\
\hline HHDDT_03 & 6.54 & 6.55 & 3.98 & 3.95 & 0.74 \\
\hline HHDDT_04 & 6.60 & 6.64 & 3.94 & 3.89 & 1.22 \\
\hline HHDDT_05 & 6.60 & 6.60 & 3.95 & 3.93 & 0.61 \\
\hline COMMUT_05 & 5.97 & 5.87 & 0.67 & 0.67 & -1.01 \\
\hline COMMUT_07 & 5.97 & 5.88 & 0.66 & 0.67 & -0.72 \\
\hline COMMUT_08 & 6.01 & 5.90 & 0.66 & 0.67 & -1.10 \\
\hline COMMUT_09 & 5.99 & 5.92 & 0.66 & 0.66 & -0.41 \\
\hline COMMUT_10 & 6.00 & 5.92 & 0.66 & 0.67 & -0.71 \\
\hline COMMUT_11 & 6.47 & 6.52 & 1.58 & 1.55 & 1.69 \\
\hline HWFET_03 & 6.56 & 6.51 & 1.56 & 1.55 & 0.23 \\
\hline HWFET_04 & 6.55 & 6.47 & 1.55 & 1.57 & -0.83 \\
\hline HWFET_05 & 6.54 & 6.44 & 1.56 & 1.57 & -0.80 \\
\hline HWFET_06 & 6.48 & 6.53 & 1.57 & 1.55 & 1.23 \\
\hline Mean & 6.34 & 6.30 & 1.93 & 1.92 & 0.06 \\
\hline
\end{tabular}


Figure 15 shows the real-time fueling scatter plot of the adjusted CAN FC and fuel scale use and the percent difference bins of exampled drive cycles, and Figure 16 demonstrates the parity plots for day cab renewable-diesel tractor. By comparing Table 4 with Table 10 and Figure 7 with Figure 16, we can see that the accuracy of adjusted CAN FC was remarkably improved.

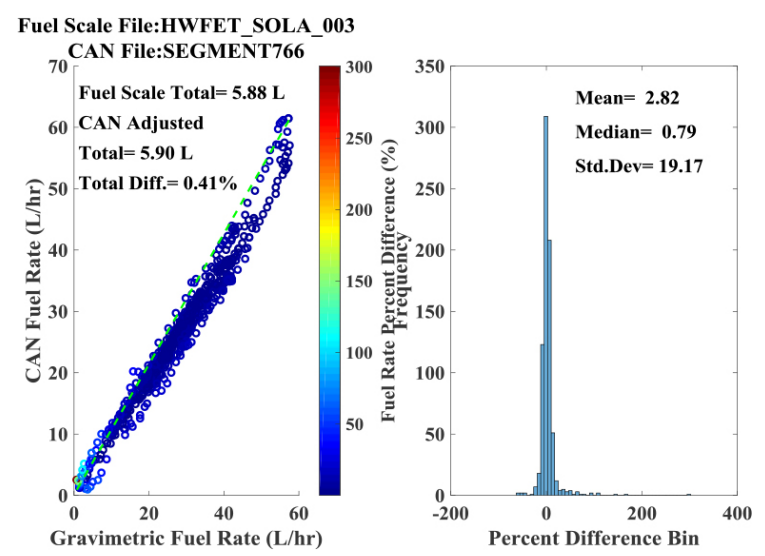

Figure 15. Real-time fuel rate parity plot between adjusted CAN FC and fuel-scale measurement and percent difference for the day cab renewablediesel tractor (30-second smoothed window)
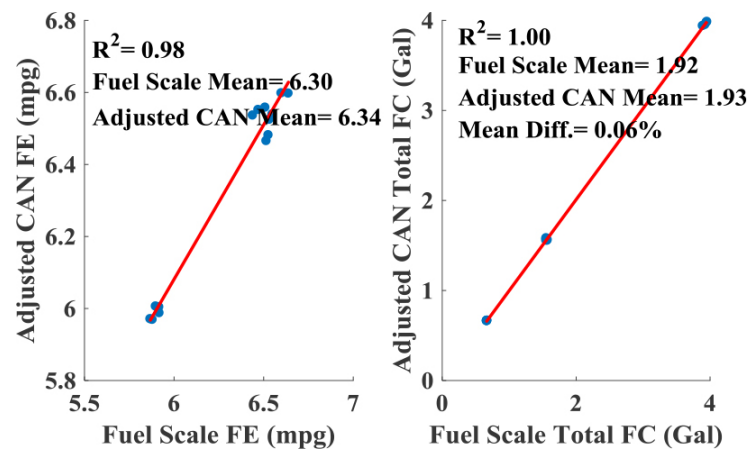

Figure 16. FE and FC parity plot between adjusted CAN FC and fuel-scale measurement for the day cab renewable-diesel tractor (30-second smoothed window)

\section{Robustness Testing of the Correction Model}

The training cycles of the correction models should be cycles that include a variety of drive characteristics, such as high speed, acceleration, idling, and deceleration. The training drive cycle was chosen by randomly selecting one test from each drive cycle, then adding them together. For example, for the medium-duty diesel conventional parcel delivery truck, the training drive cycle included the CSHVC_02, HHDDT_02, HHV_02 and NYC_02 drive cycles. $\underline{\text { Tables } 11}, \underline{12}, \underline{13}$ show the performance results by applying the optimal correction models using multiple drive cycles as training data. The mean relative differences were reduced from $7.41 \%$, $-5.31 \%$, and $6.51 \%$ to $0.84 \%, 0.33 \%$, and $-0.30 \%$ for the mediumduty diesel conventional parcel delivery truck, the medium-duty hydraulic hybrid parcel delivery truck, and the day cab renewablediesel tractor, respectively.
Table 11. Comparison of adjusted CAN FC against fuel-scale measurement for the medium-duty diesel conventional parcel delivery truck when applying optimal model with multiple drive cycles as training data (30-second smoothed window)

\begin{tabular}{|l|l|l|l|l|l|}
\hline Drive Cycle & $\begin{array}{l}\text { Adjusted } \\
\text { CAN FE } \\
\text { (mpg) }\end{array}$ & $\begin{array}{l}\text { Fuel } \\
\text { Scale } \\
\text { FE } \\
\text { (mpg) }\end{array}$ & $\begin{array}{l}\text { Adjusted } \\
\text { CAN FC } \\
\text { (gal) }\end{array}$ & $\begin{array}{l}\text { Fuel } \\
\text { Scale } \\
\text { FC } \\
\text { (gal) }\end{array}$ & $\begin{array}{l}\text { FC } \\
\text { Relative } \\
\text { Diff. } \\
\text { (\%) }\end{array}$ \\
\hline CSHVC_1 & 9.30 & 9.57 & 0.72 & 0.70 & 2.94 \\
\hline CSHVC_2 & 9.38 & 9.57 & 0.71 & 0.70 & 1.65 \\
\hline CSHVC_3 & 9.41 & 9.48 & 0.71 & 0.70 & 0.53 \\
\hline CSHVC_4 & 9.34 & 9.51 & 0.71 & 0.70 & 1.50 \\
\hline CSHVC_5 & 9.43 & 9.40 & 0.70 & 0.71 & -0.64 \\
\hline HHDDT_1 & 11.60 & 12.12 & 2.24 & 2.15 & 4.06 \\
\hline HHDDT_2 & 11.20 & 11.38 & 2.31 & 2.29 & 1.19 \\
\hline HHDDT_4 & 11.17 & 11.51 & 2.33 & 2.26 & 2.91 \\
\hline HHDDT_5 & 11.22 & 11.49 & 2.32 & 2.27 & 2.17 \\
\hline HHV_1 & 8.23 & 8.25 & 2.48 & 2.48 & 0.28 \\
\hline HHV_2 & 8.57 & 8.44 & 2.37 & 2.41 & -1.62 \\
\hline HHV_3 & 8.69 & 8.56 & 2.35 & 2.38 & -1.53 \\
\hline HHV_4 & 8.69 & 8.61 & 2.35 & 2.37 & -0.98 \\
\hline NYC_1 & 6.84 & 6.80 & 0.37 & 0.37 & -0.67 \\
\hline NYC_2 & 7.06 & 7.07 & 0.36 & 0.36 & 0.15 \\
\hline NYC_3 & 7.08 & 7.17 & 0.35 & 0.35 & 1.22 \\
\hline NYC_4 & 7.20 & 7.27 & 0.35 & 0.34 & 1.18 \\
\hline Mean & 9.08 & 9.19 & 1.40 & 1.38 & 0.84 \\
\hline & & & & & \\
\hline
\end{tabular}

Table 12. Comparison of adjusted CAN FC against fuel-scale measurement for medium-duty hydraulic parcel delivery truck when applying optimal model with multiple drive cycles as training data (120-second smoothed window)

\begin{tabular}{|l|l|l|l|l|l|}
\hline Drive Cycle & $\begin{array}{l}\text { CAN } \\
\text { FE } \\
\text { (mpg) }\end{array}$ & $\begin{array}{l}\text { Fuel } \\
\text { Scale } \\
\text { FE } \\
\text { (mpg) }\end{array}$ & $\begin{array}{l}\text { FC } \\
\text { (gal) }\end{array}$ & $\begin{array}{l}\text { Fuel } \\
\text { Scale } \\
\text { FC } \\
\text { (gal) }\end{array}$ & $\begin{array}{l}\text { FC } \\
\text { Relative } \\
\text { Diff. } \\
(\%)\end{array}$ \\
\hline NYCC_02 & 10.80 & 10.67 & 0.23 & 0.23 & -2.69 \\
\hline NYCC_03 & 10.81 & 10.76 & 0.23 & 0.23 & -1.80 \\
\hline NYCC_04 & 11.05 & 11.11 & 0.22 & 0.23 & -0.96 \\
\hline NYCC_05 & 10.96 & 10.84 & 0.22 & 0.23 & -2.45 \\
\hline CSHVC_01 & 12.65 & 13.40 & 0.52 & 0.50 & 4.68 \\
\hline CSHVC_02 & 12.70 & 12.95 & 0.52 & 0.51 & 0.71 \\
\hline CSHVC_03 & 12.49 & 12.79 & 0.53 & 0.52 & 1.19 \\
\hline CSHVC_04 & 12.62 & 12.84 & 0.52 & 0.52 & 0.48 \\
\hline CSHVC_05 & 12.60 & 12.76 & 0.52 & 0.52 & 0.02 \\
\hline HHDDT_01 & 11.91 & 12.20 & 2.17 & 2.13 & 1.46 \\
\hline HHDDT_02 & 10.94 & 10.96 & 2.36 & 2.38 & -0.77 \\
\hline HHDDT_03 & 11.18 & 11.31 & 2.31 & 2.30 & 0.25 \\
\hline HHDDT_04 & 11.20 & 11.30 & 2.30 & 2.30 & -0.05 \\
\hline HHDDT_05 & 11.45 & 11.63 & 2.25 & 2.24 & 0.65 \\
\hline HHDDT_06 & 11.12 & 11.27 & 2.32 & 2.31 & 0.49 \\
\hline HHV_01 & 10.35 & 10.65 & 1.87 & 1.84 & 1.58 \\
\hline HHV_02 & 9.91 & 10.14 & 2.00 & 1.98 & 0.91 \\
\hline HHV_03 & 9.98 & 10.24 & 1.98 & 1.96 & 1.31 \\
\hline HHV_04 & 9.94 & 10.21 & 1.99 & 1.97 & 1.31 \\
\hline & 11.30 & 11.47 & 1.32 & 1.31 & 0.33 \\
\hline
\end{tabular}


Table 13. Comparison of adjusted CAN FC against fuel-scale measurement for day cab renewable-diesel tractor when applying optimal model with multiple drive cycles as training data (30-second smoothed window)

\begin{tabular}{|c|c|c|c|c|c|}
\hline Drive Cycle & $\begin{array}{l}\text { CAN } \\
\text { FE } \\
(m p g)\end{array}$ & $\begin{array}{l}\text { Fuel } \\
\text { Scale } \\
\text { FE } \\
\text { (mpg) }\end{array}$ & $\begin{array}{l}\text { CAN } \\
\text { FC } \\
\text { (gal) }\end{array}$ & $\begin{array}{l}\text { Fuel } \\
\text { Scale } \\
\text { FC } \\
\text { (gal) }\end{array}$ & $\begin{array}{l}\text { FC } \\
\text { Relative } \\
\text { Diff. (\%) }\end{array}$ \\
\hline HHDDT_02 & 6.53 & 6.53 & 3.95 & 3.96 & -0.02 \\
\hline HHDDT_03 & 6.59 & 6.55 & 3.95 & 3.95 & -0.01 \\
\hline HHDDT_04 & 6.65 & 6.64 & 3.91 & 3.89 & 0.47 \\
\hline HHDDT_05 & 6.65 & 6.60 & 3.92 & 3.93 & -0.13 \\
\hline COMMUT 05 & 5.99 & 5.87 & 0.66 & 0.67 & -1.26 \\
\hline COMMUT_07 & 5.98 & 5.88 & 0.66 & 0.67 & -0.98 \\
\hline COMMUT_08 & 6.02 & 5.90 & 0.66 & 0.67 & -1.35 \\
\hline COMMUT_09 & 6.00 & 5.92 & 0.66 & 0.66 & -0.66 \\
\hline COMMUT_10 & 6.02 & 5.92 & 0.66 & 0.67 & -0.96 \\
\hline COMMUT_11 & 6.48 & 6.52 & 1.58 & 1.55 & 1.53 \\
\hline HWFET 03 & 6.57 & 6.51 & 1.55 & 1.55 & 0.07 \\
\hline HWFET 04 & 6.56 & 6.47 & 1.55 & 1.57 & -0.98 \\
\hline HWFET_05 & 6.55 & 6.44 & 1.56 & 1.57 & -0.96 \\
\hline HWFET_06 & 6.49 & 6.53 & 1.57 & 1.55 & 1.07 \\
\hline Mean & 6.37 & 6.30 & 1.92 & 1.92 & -0.30 \\
\hline
\end{tabular}

\section{Summary}

The CAN-broadcasted FC showed discrepancies with measurement using a precise gravimetric fuel scale. To use the easily acquired CAN-broadcasted FC with confidence, models were developed to correct the CAN-broadcasted fuel use. Calibration of the developed model included selecting the most effective input parameters and training drive cycles as training data. The top three best models were obtained when the correction models were expressed as the adjusted CAN FCs as functions of the original CAN FC only; the original CAN and vehicle speed; and the original CAN, vehicle speed and vehicle acceleration. The training data should be cycles that contain a variety of drive characteristics, such as high speed, acceleration, idling, and deceleration.

By applying the optimal correction models with multiple drive cycles as training data, the mean relative differences were reduced from $7.41 \%,-5.31 \%$, and $6.51 \%$ to $0.84 \%, 0.33 \%$, and $-0.30 \%$, respectively for the three trucks investigated.
Future work should apply this methodology to a broader range of vehicle types.

\section{References}

1. Surcel, M. and Michaelsen, J., "Fuel Consumption Tests for Evaluating the Accuracy and Precision of Truck Engine Electronic Control Modules to Capture Fuel Data," SAE Technical Paper 2009-01-1605, 2009, https://doi. org/10.4271/2009-01-1605.

2. Performance Innovation Transport Group. 2015. "Is ECM Data Accurate Enough to Use When Making Decisions about Fuel Saving Technologies or Operational Practices." PIT Innovations. http://thepitgroup.com/wp-content/uploads/2015/10/ECM-CaseStudy-A-PIT-Group-Case-Study.pdf

3. Pink, A., Ragatz, A., Wang, L., Wood, E. et al., "Comparison of Vehicle-Broadcasted Fuel Consumption Rates against Precise Fuel Measurements for Medium- and Heavy-Duty Vehicles and Engines," SAE Int. J. Fuels Lubr. 10(2):574-582, 2017, https:// doi.org/10.4271/2017-01-0901.

4. Messer, J., Clark, N., and Lyons, D., "Measurement Delays and Modal Analysis for a Heavy Duty Transportable Emissions Testing Laboratory," SAE Technical Paper 950218, 1995, https://doi.org/10.4271/950218.

5. Wang, L., Duran, A., Gonder, J., and Kelly, K., "Modeling Heavy/Medium-Duty Fuel Consumption Based on Drive Cycle Properties," SAE Technical Paper 2015-01-2812, 2015, https:// doi.org/10.4271/2015-01-2812.

\section{Acknowledgment}

This work was supported by the U.S. Department of Energy under Contract No. DE-AC36-08GO28308 with Alliance for Sustainable Energy, LLC, the Manager and Operator of the National Renewable Energy Laboratory. Funding provided by the U.S. Department of Energy Office of Energy Efficiency and Renewable Energy Vehicle Technologies Office. The U.S. Government retains and the publisher, by accepting the article for publication, acknowledges that the U.S. Government retains a nonexclusive, paid-up, irrevocable, worldwide license to publish or reproduce the published form of this work, or allow others to do so, for U.S. Government purposes.

\section{Definitions/Abbreviations}

CAN - controller area network

FC - fuel consumption

FE - fuel economy

ReFUEL - Renewable Fuels and Lubricants

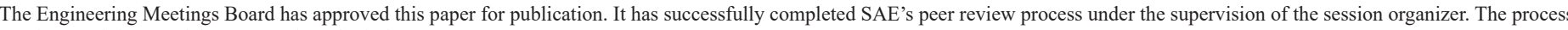
requires a minimum of three (3) reviews by industry experts.

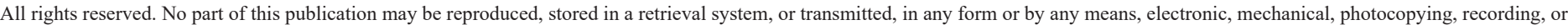
otherwise, without the prior written permission of SAE International.

Positions and opinions advanced in this paper are those of the author(s) and not necessarily those of SAE International. The author is solely responsible for the content of the paper

ISSN 0148-7191 